Hope College

Hope College Digital Commons

$4-17-2020$

\title{
Using Remote Sensing to Monitor Ecohydrological Changes in Great Lakes Interdunal Wetlands/Slacks
}

\author{
Rene Aerts \\ Hope College \\ Katherine Kay \\ Hope College
}

Follow this and additional works at: https://digitalcommons.hope.edu/curca_19

Part of the Environmental Sciences Commons, and the Geology Commons

\section{Recommended Citation \\ Repository citation: Aerts, Rene and Kay, Katherine, "Using Remote Sensing to Monitor Ecohydrological Changes in Great Lakes Interdunal Wetlands/Slacks" (2020). 19th Annual Celebration of Undergraduate Research and Creative Activity (2020). Paper 24. https://digitalcommons.hope.edu/curca_19/24 April 17, 2020. Copyright @ 2020 Hope College, Holland, Michigan.}

This Poster is brought to you for free and open access by the Celebration of Undergraduate Research and Creative Activity at Hope College Digital Commons. It has been accepted for inclusion in 19th Annual Celebration of Undergraduate Research and Creative Activity (2020) by an authorized administrator of Hope College Digital Commons. For more information, please contact digitalcommons@hope.edu. 
USING REMOTE SENSING TO MONITOR ECOHYDROLOGICAL CHANGES IN GREAT LAKES INTERDUNAL WETLANDS/SLACKS

RENE AERTS ${ }^{1}$, KATHERINE KAY1, SUZANNE J. DEVRIES-ZIMMERMAN ${ }^{1}$, EDWARD C. HANSEN ${ }^{1}$, BRIAN P. YURK ${ }^{2}$, AND PAUL PEARSON

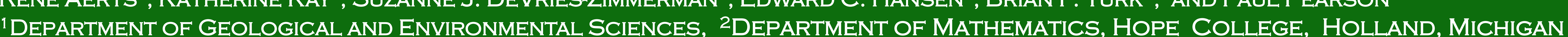

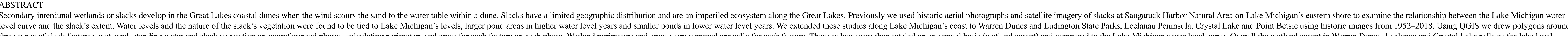

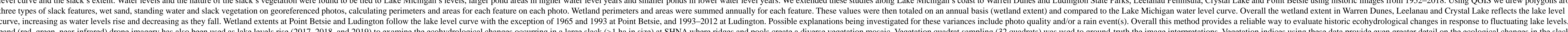

Introduction and Site Description

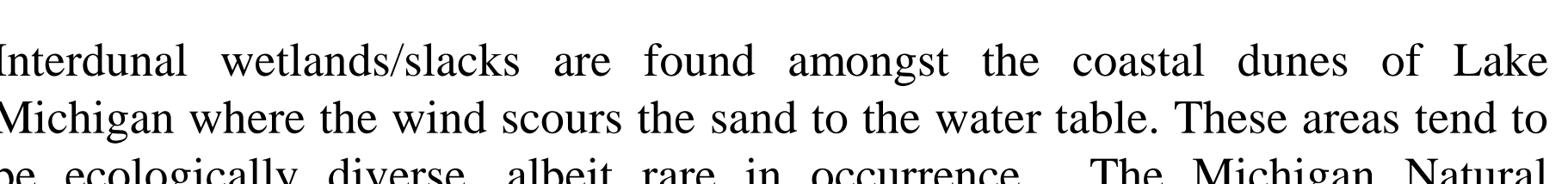

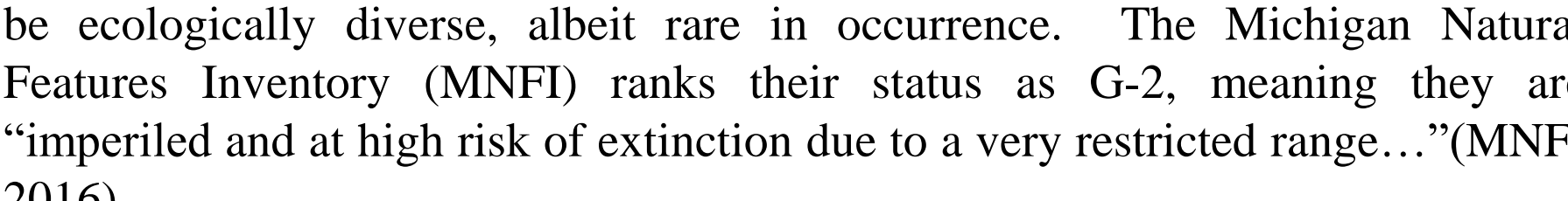

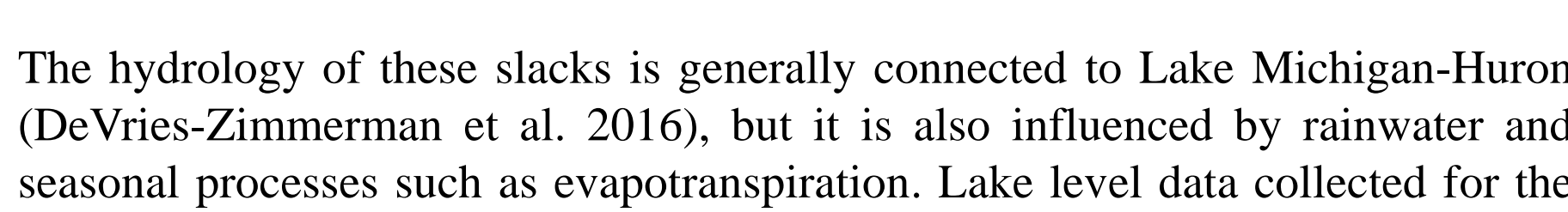

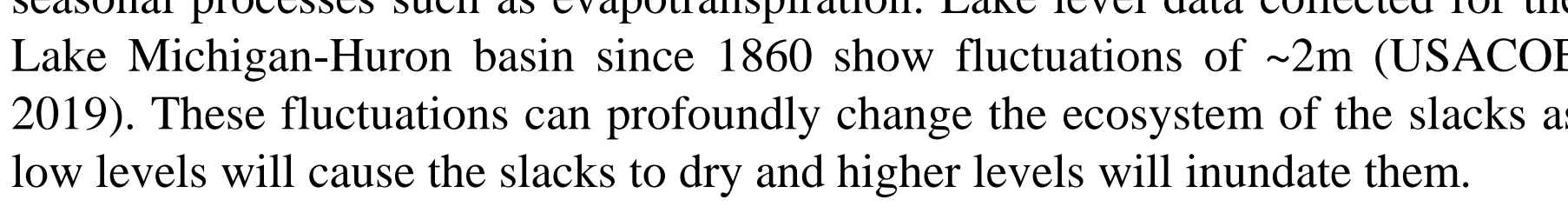

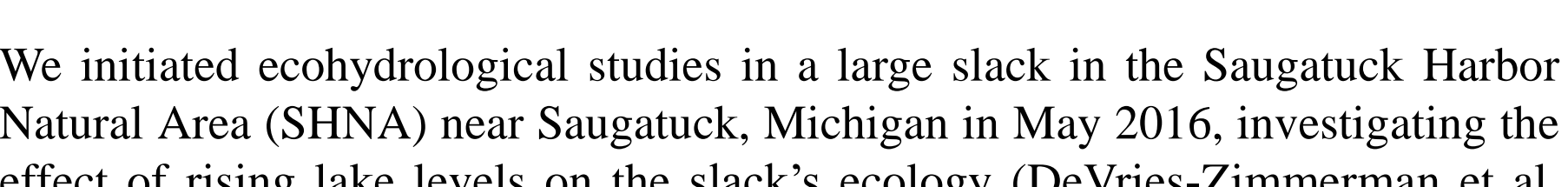

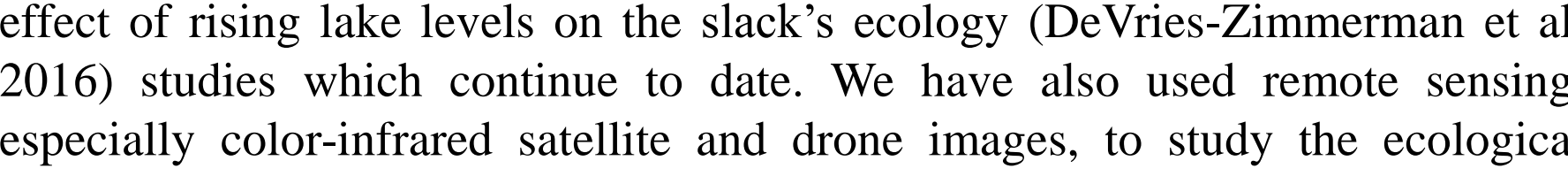

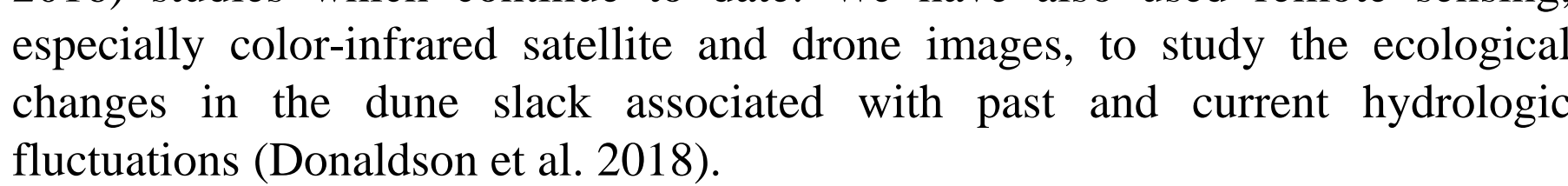

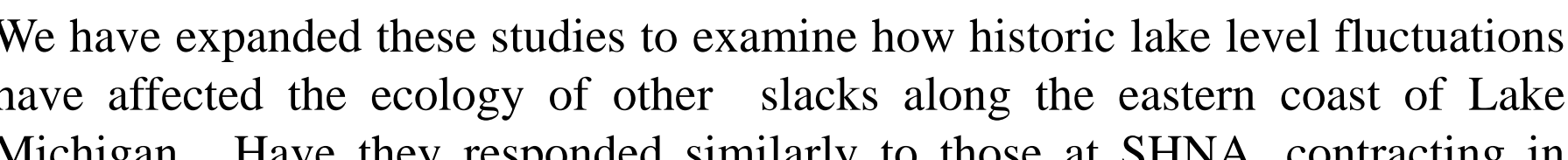

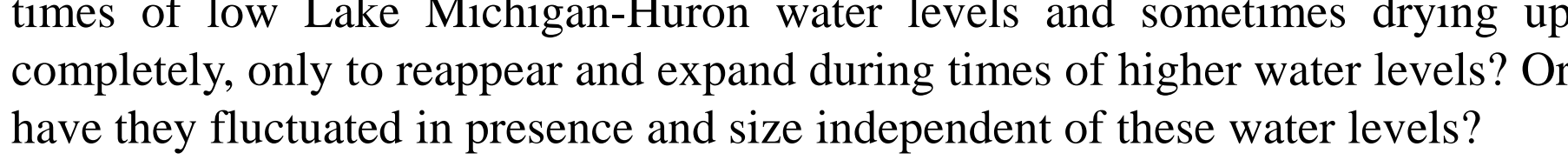
Remote Sensing Surrey - Methodolog Using Google earth, we surveyed Lake Michigan's eastern coast for slater
located within dune complexes hhat also had usable historic imagery. Historts

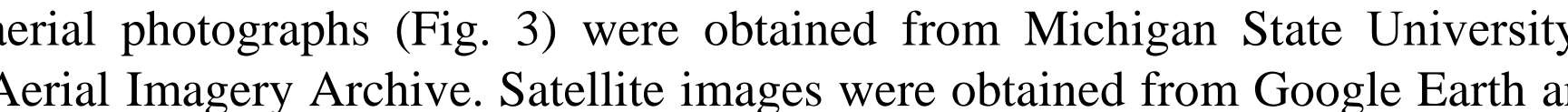

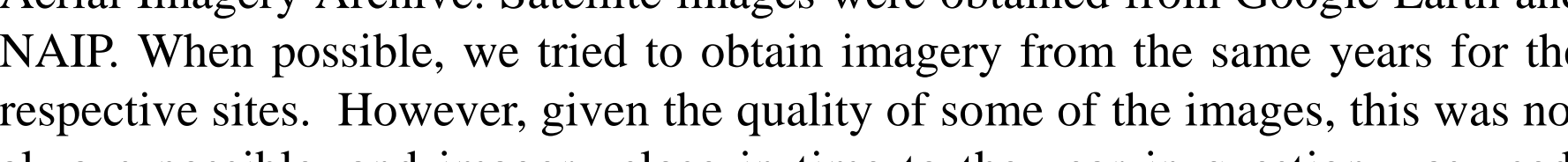

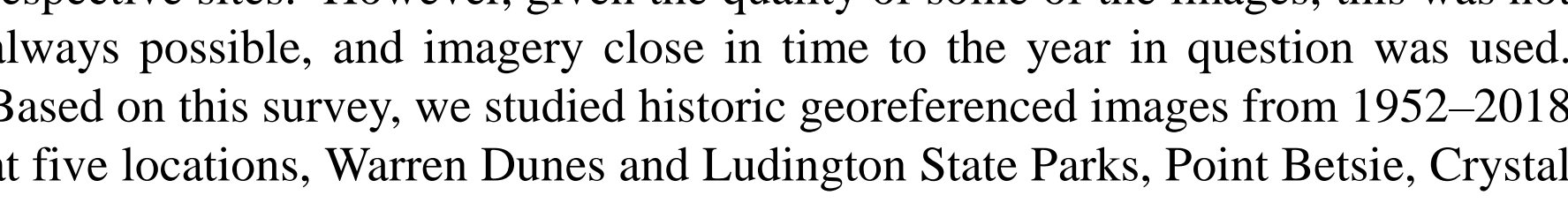

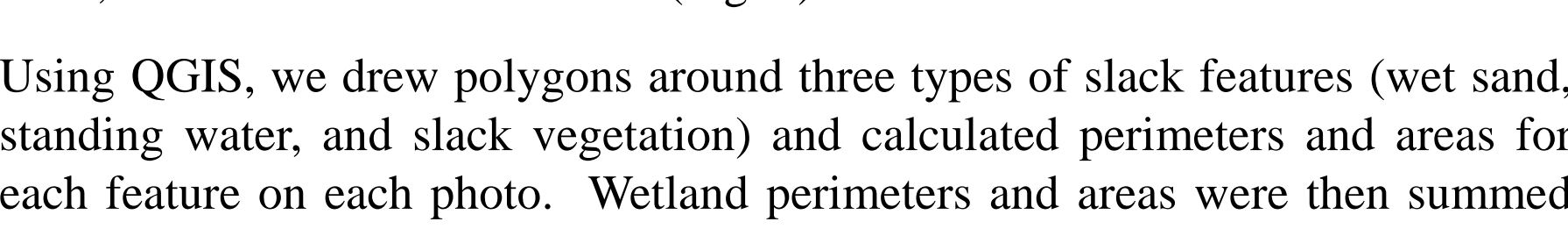

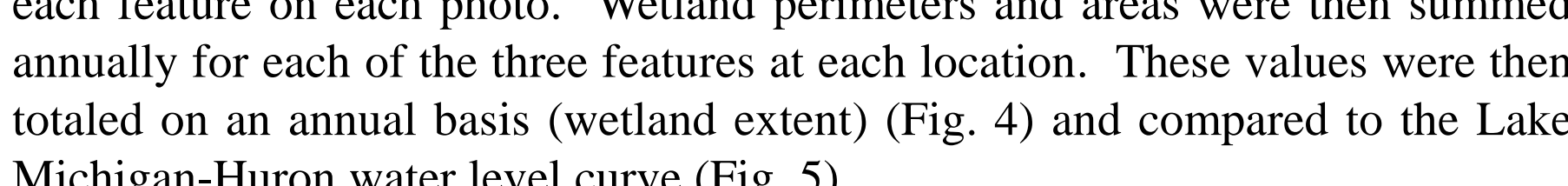
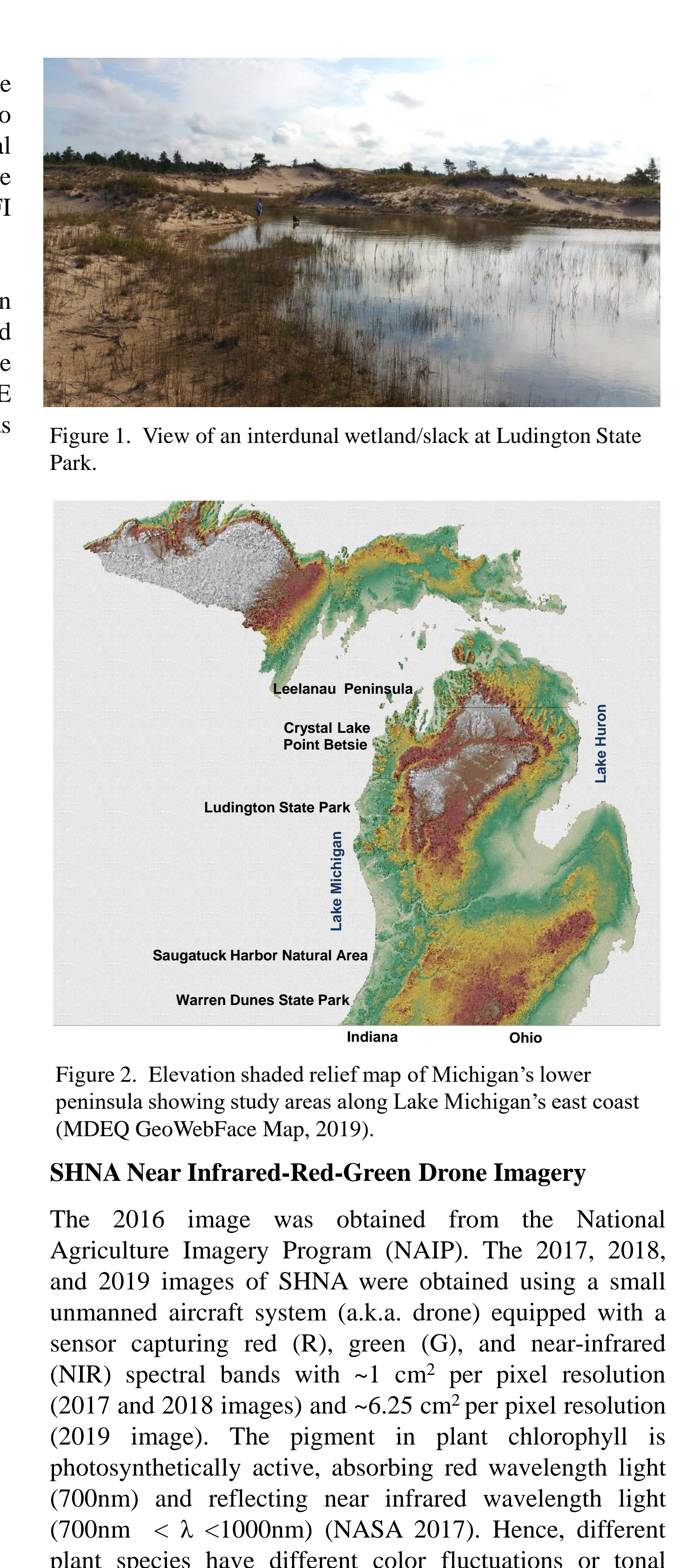

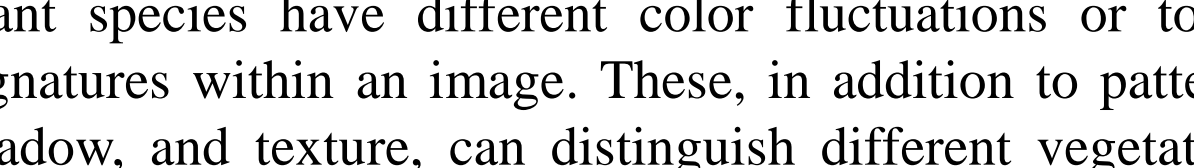

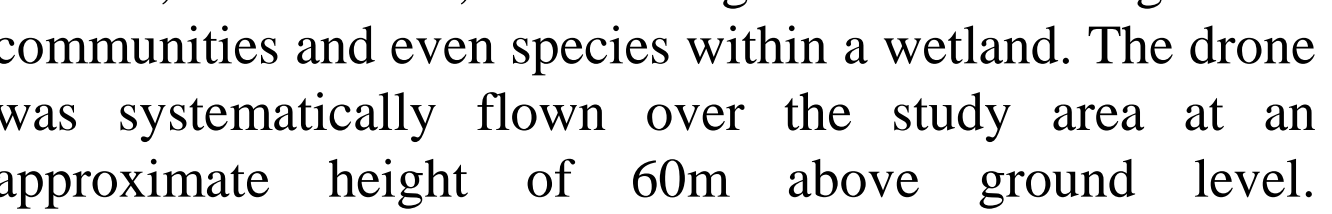

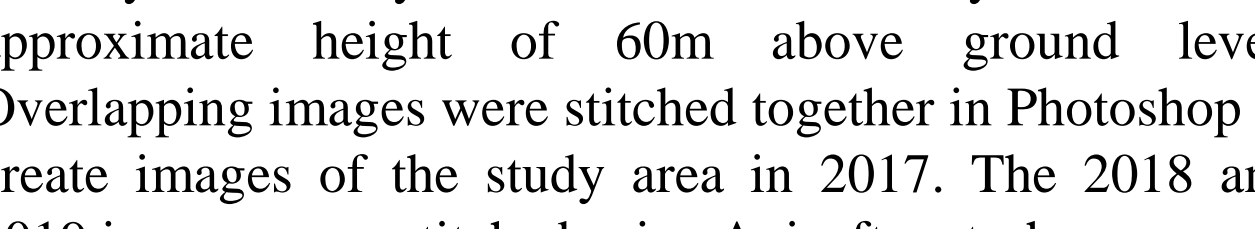

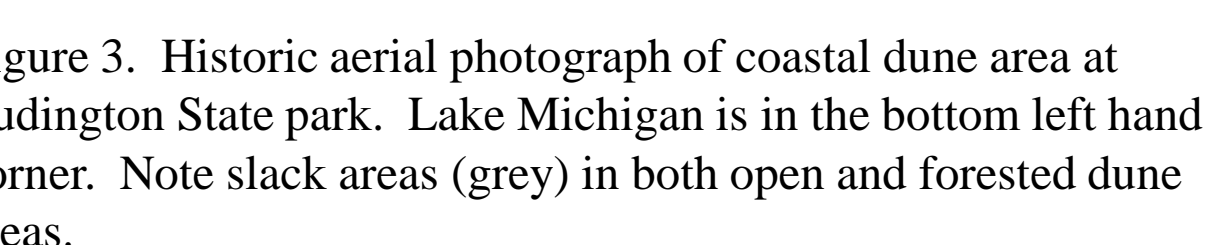

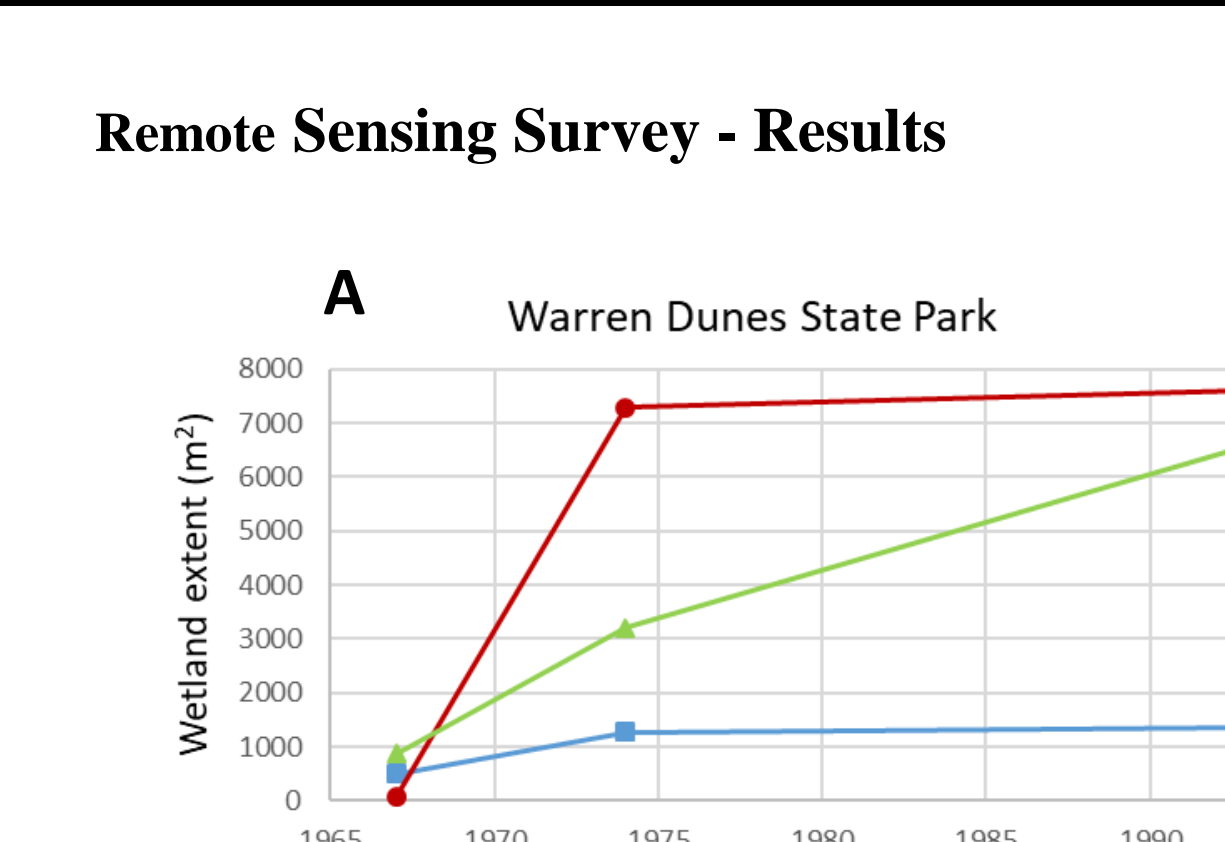

H.

B Leelanu Penins

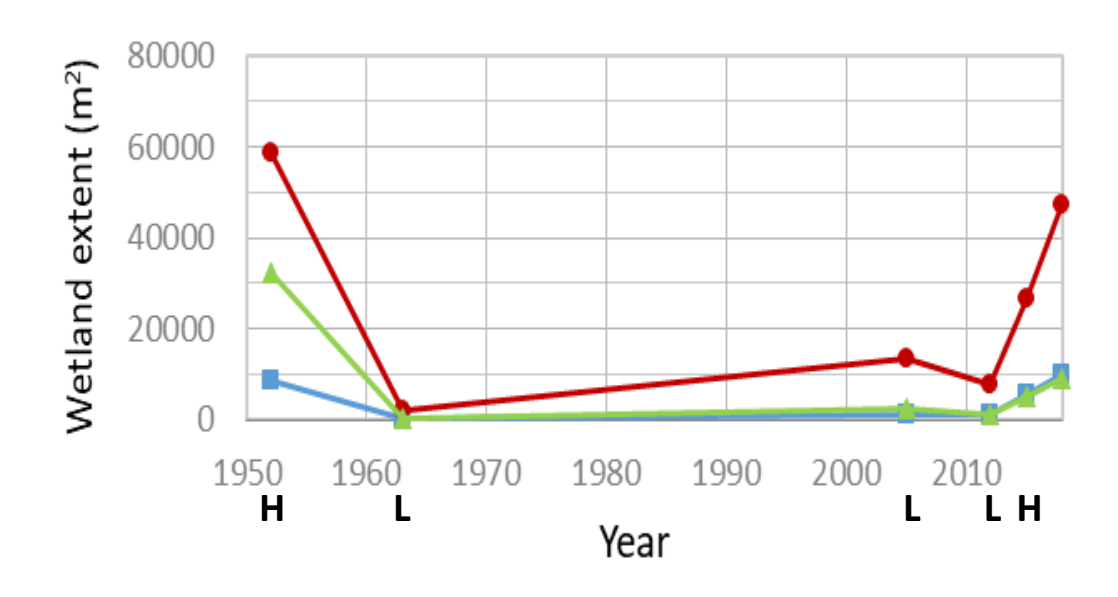

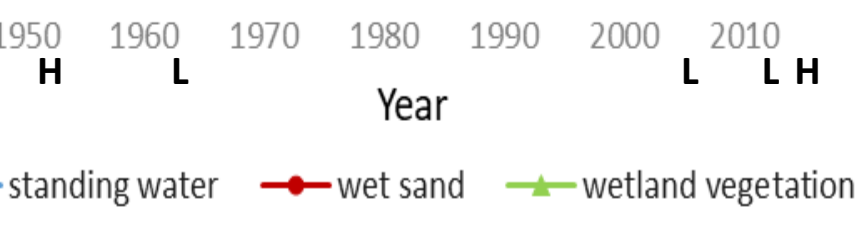

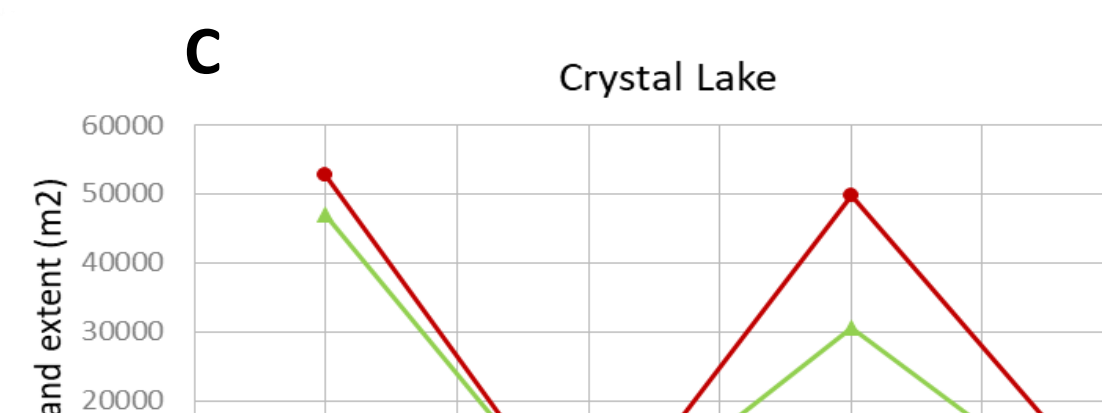

(iv

.

(1900)

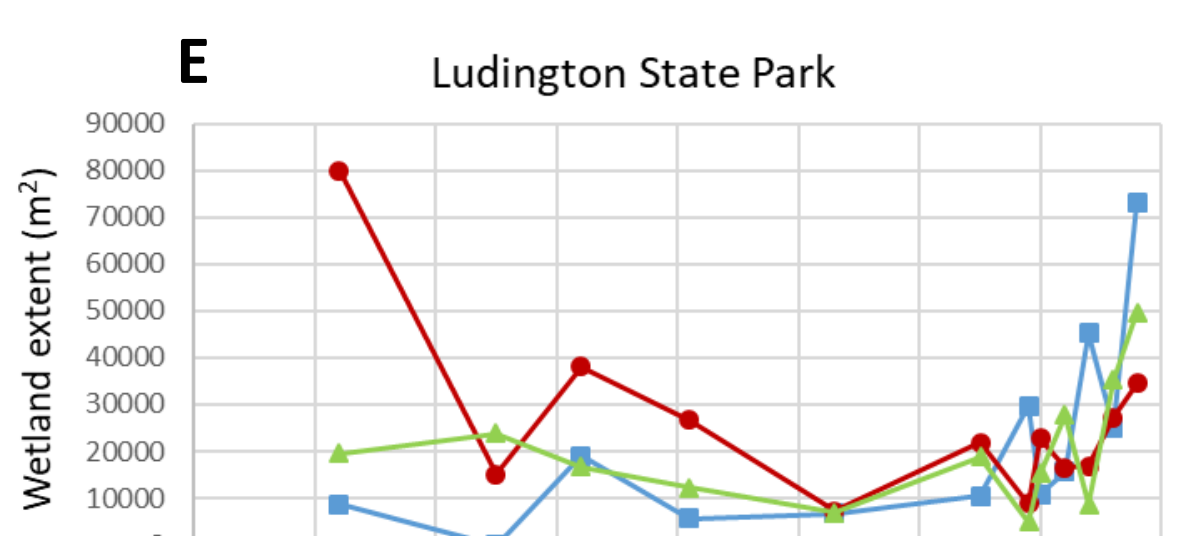

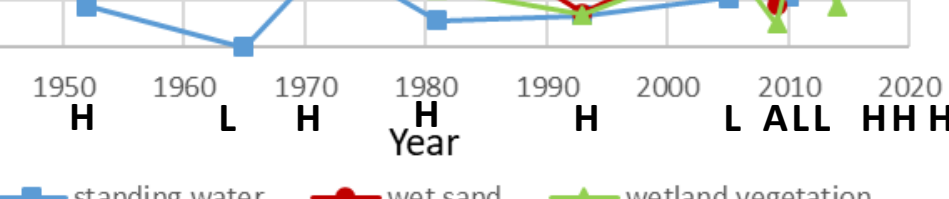

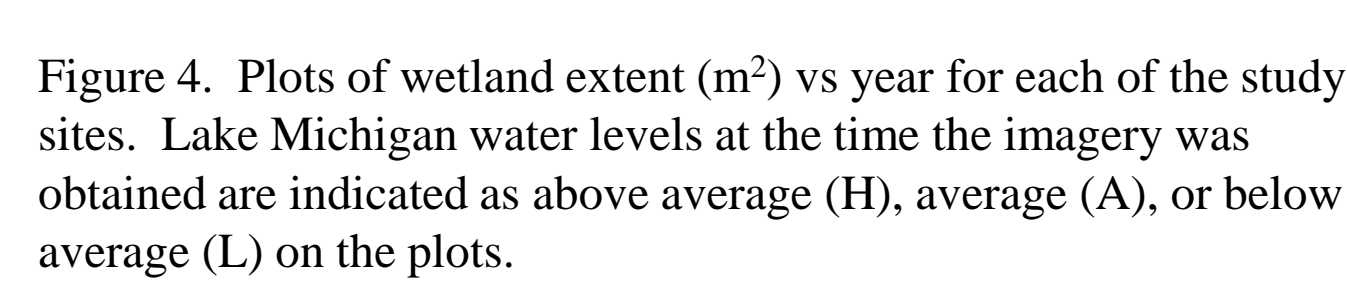

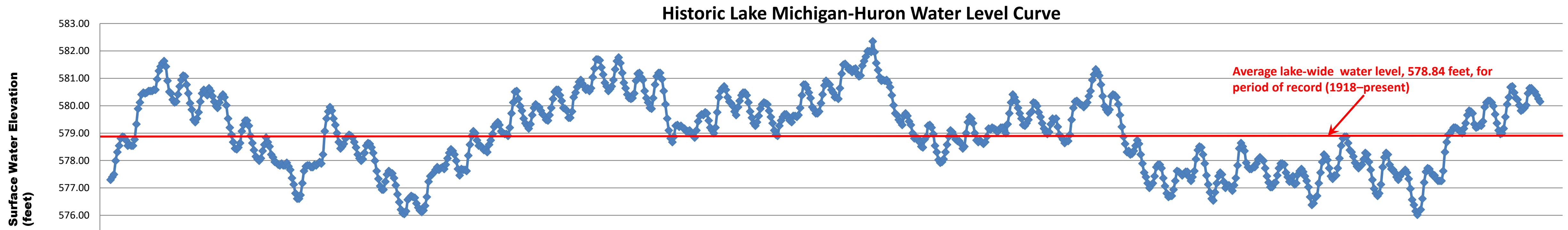

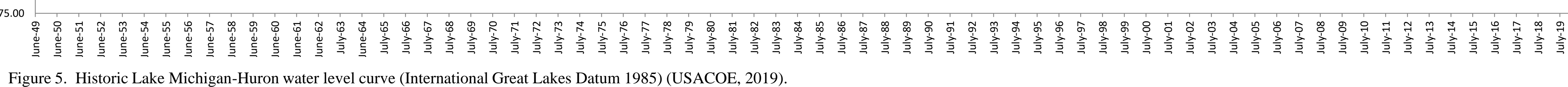

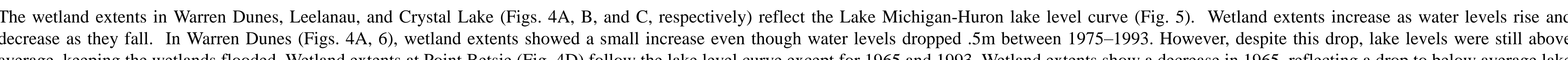

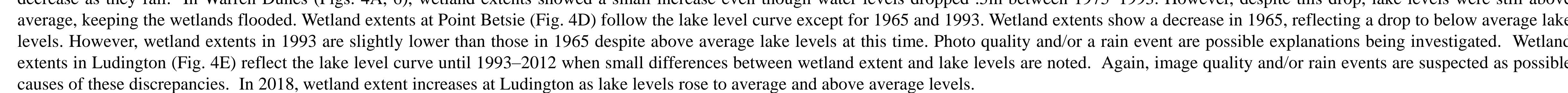
Multipectral NAIP and drone imager

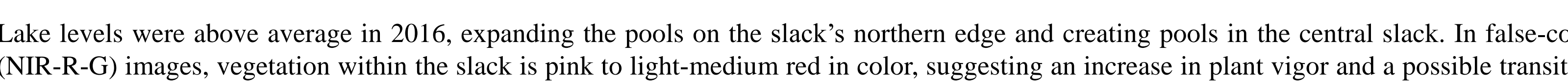

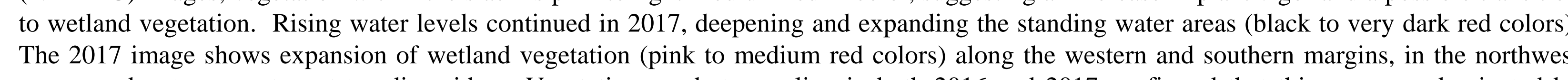

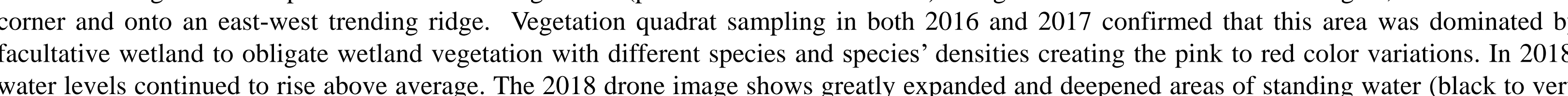

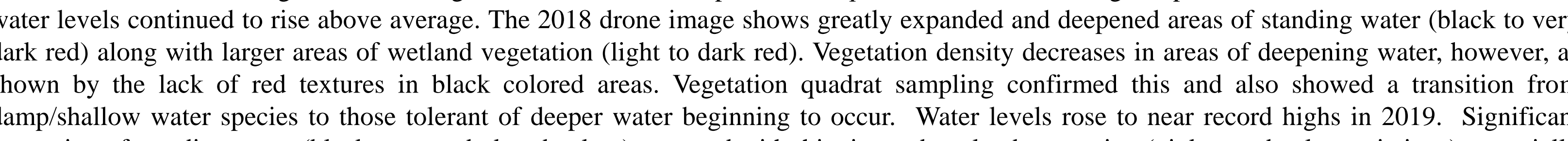

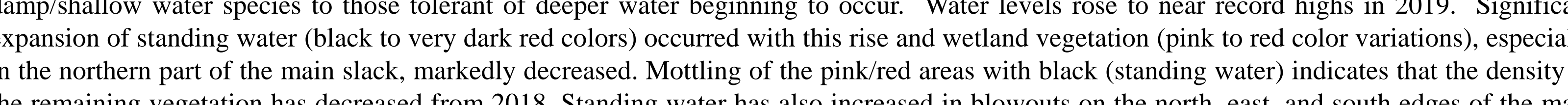

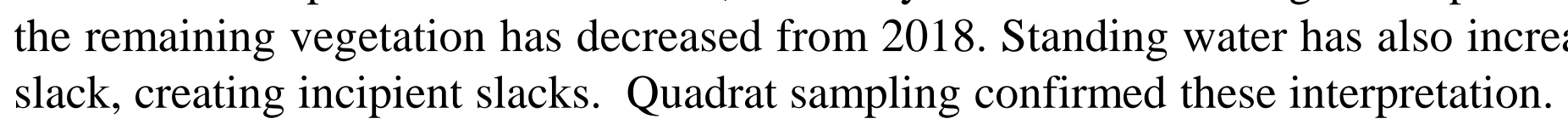

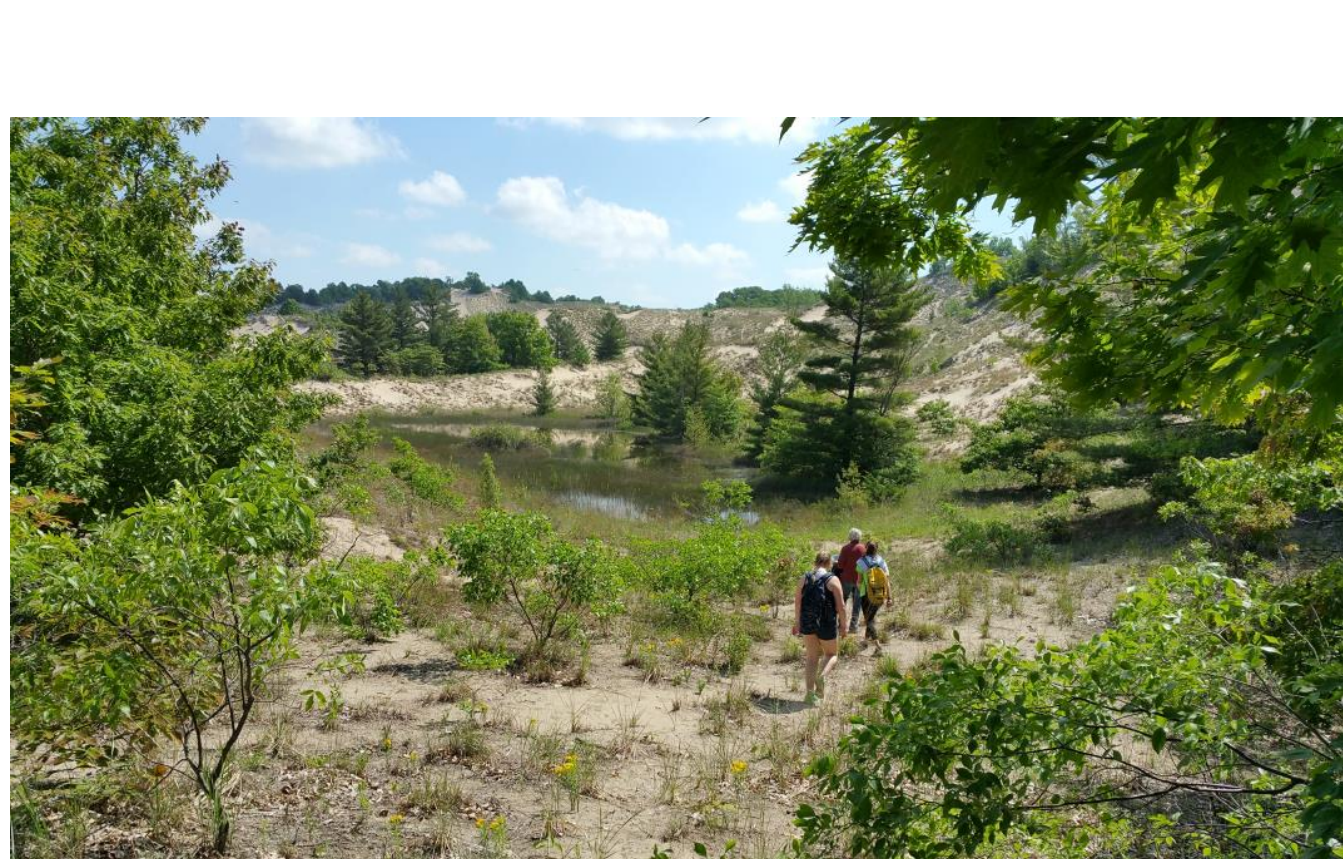
Future Work

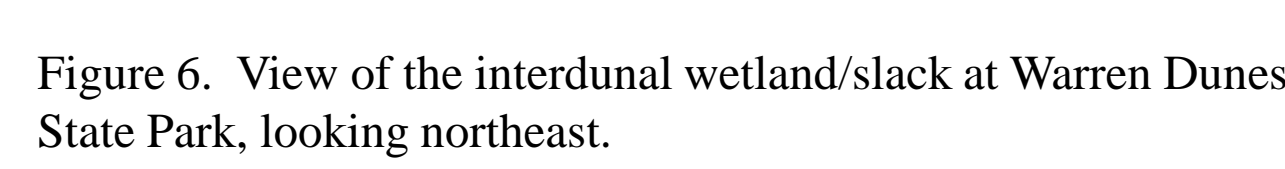

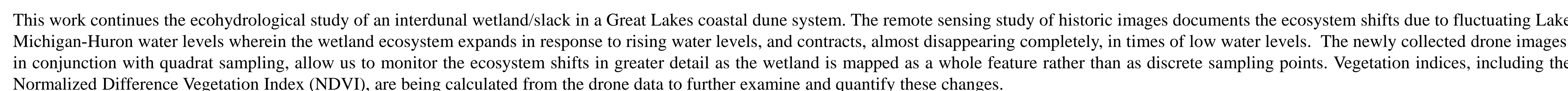
Acknowedgenents

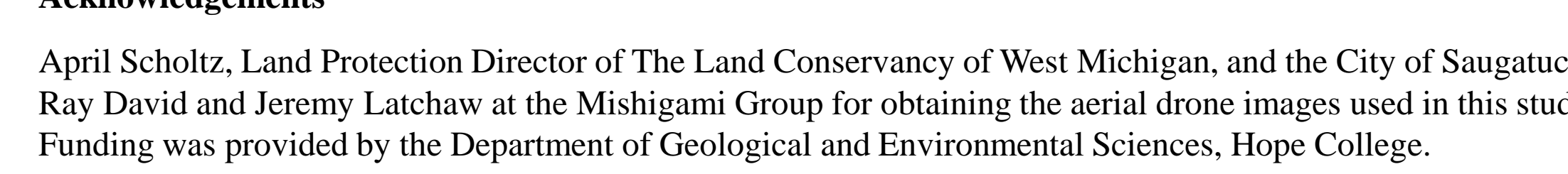

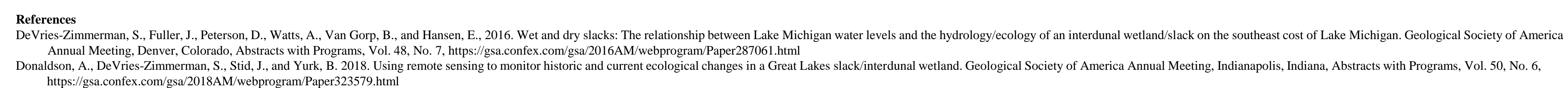

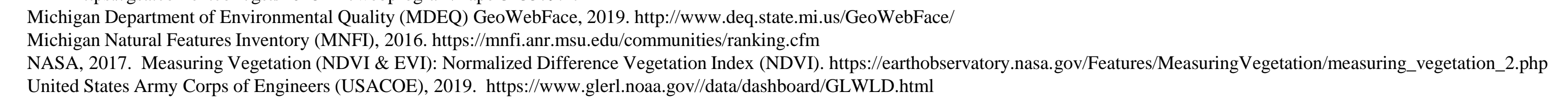
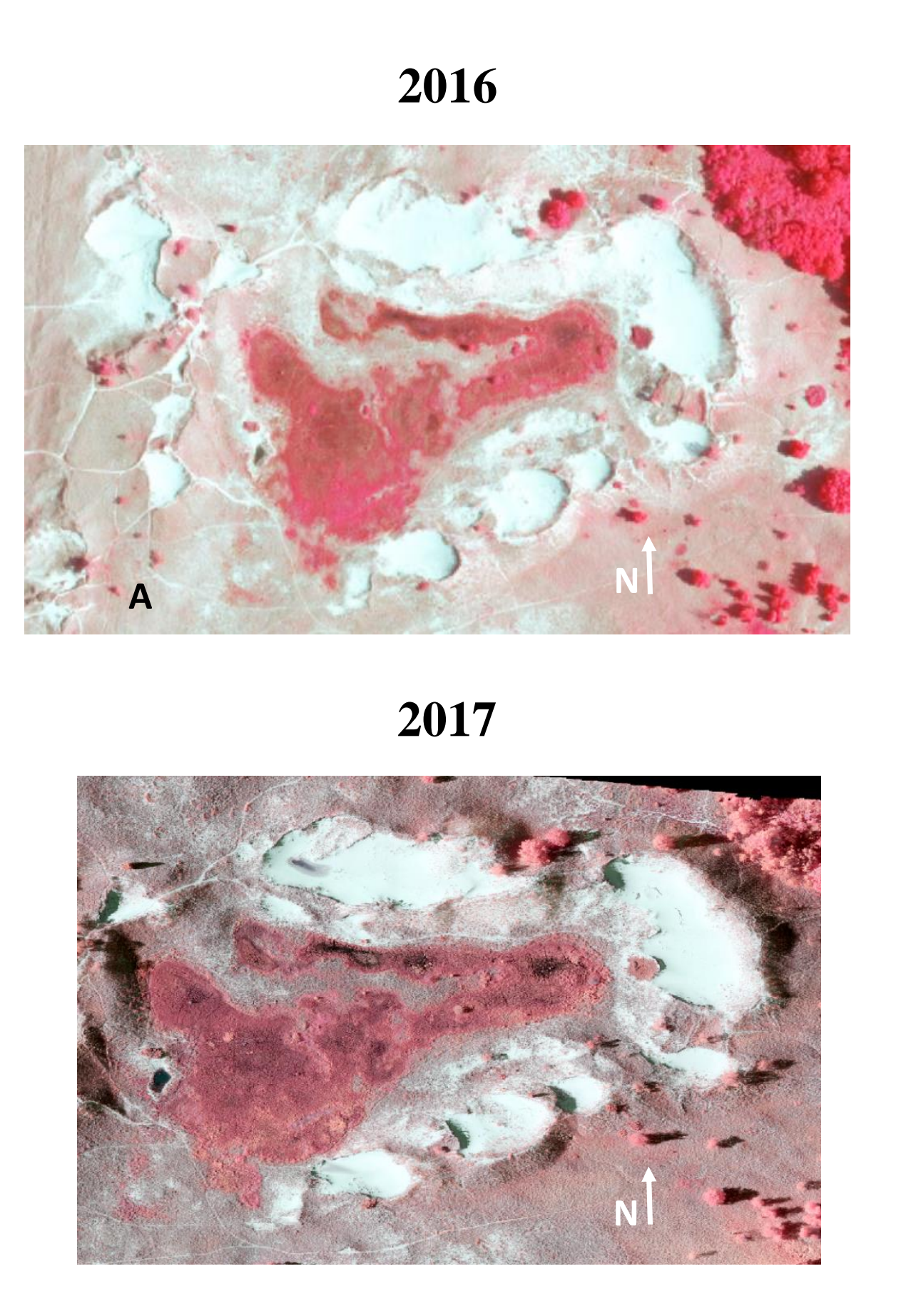

2018

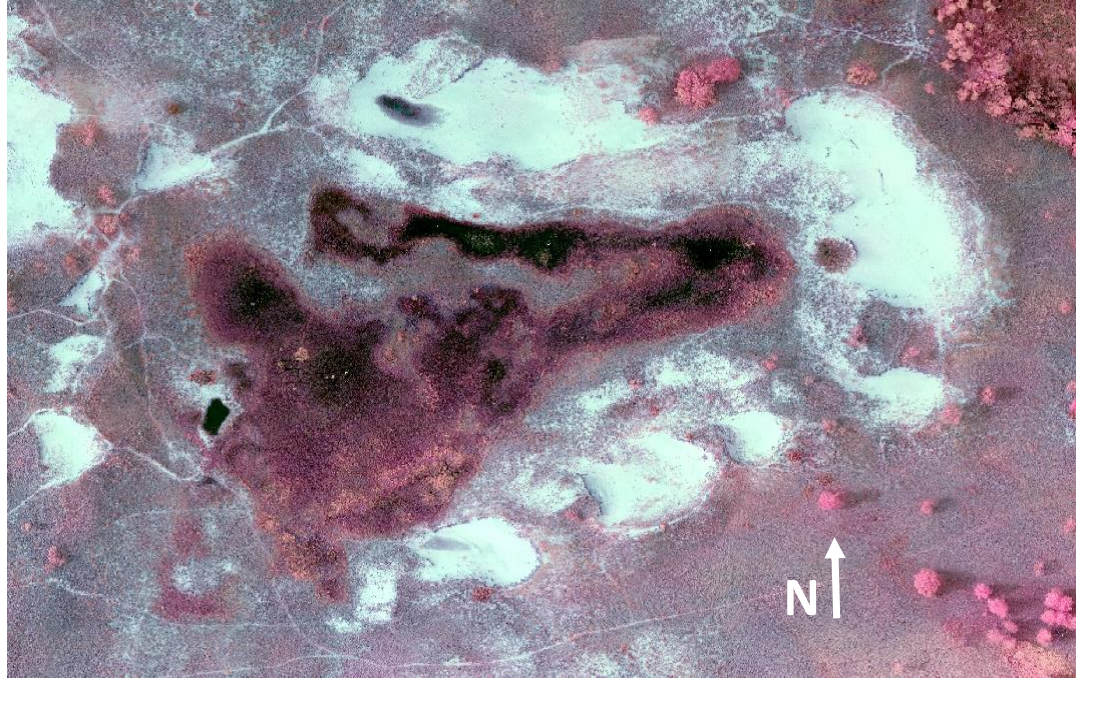

2019

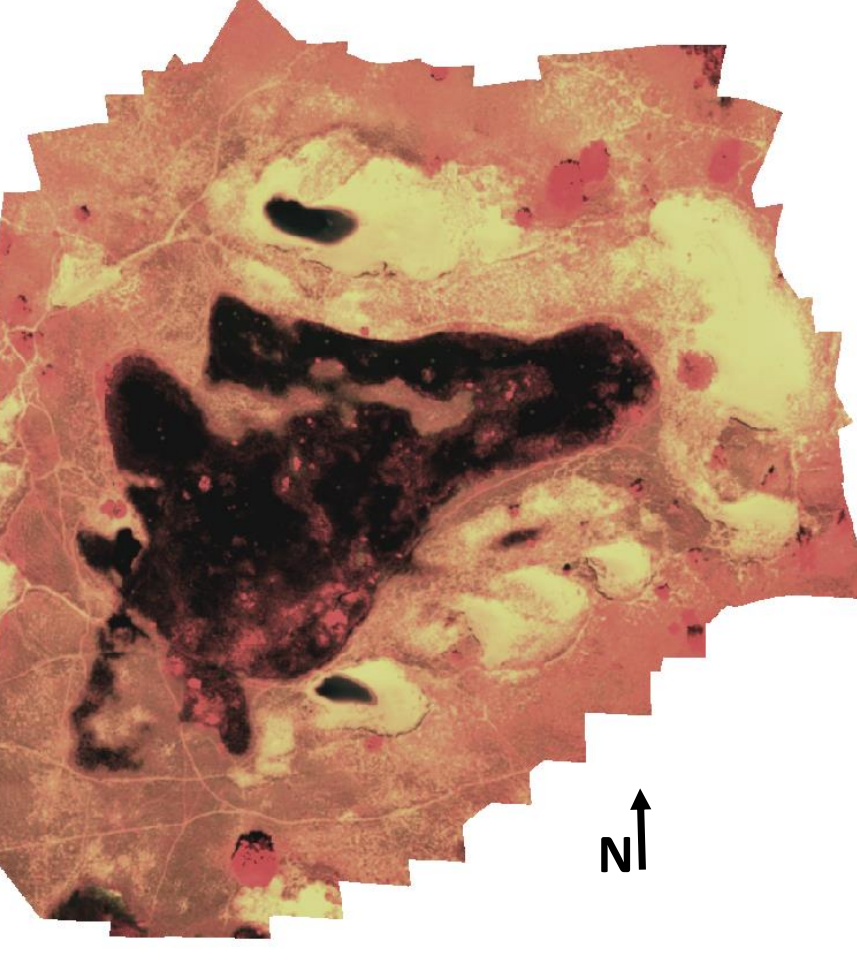

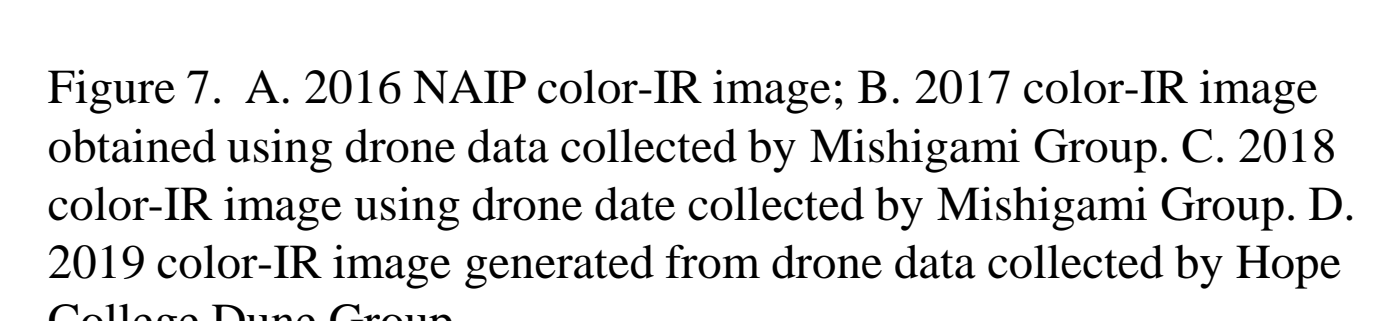

